\title{
NOTES ON X-RAY INTERPRETATION OF MARINE SEDINIENTS
}

\author{
ARNOLD H. BOUMA \\ Geological Institute, State University, Utrecht (The Netheilands)
}

(Received October 20, 1964)

\section{SUMMARY}

$X$-ray radiography is a technique recently introduced in the study of sediments. The method is very useful for analysing details of primary and sscondary sedimentary structures or to detect their presence in unconsolidated as well as in consolidated deposits. Prints of radiographs made from vertical slices of samples collected in Recent marsh, submarine canyons and estuarine environments are used to discuss the interpretation of the visible structurcs.

\section{INTRODUCTION}

X-ray radiography has already been applied for several decades to vertebrate paleontology in order to collect more details of the fossils thems lves, and of their position within the material in which they were found. It was in 1962 that this technique found its way into the study of sediments. HambLiN (1962) was the first in this field to demonstrate the use of this method in analysing so-called homogeneous sandstones. Later CALVERT and VEzVERS (1962) applied X-ray radiography to reveal minor structures in unconsolidated marine sedimonts. Thoir rosults cncouraged the present author to continue their efforts. By applying several techniques to the same samples the importance of radiography became obvious. This method certainly is not capable of solving all sedimentological questions. It must be regarded as a quick technique by which additional information can be collected that is difficult to obtain by other methods. Peeling and impregnation mothods are widely used, but especially for wet sediments only a number of time-consuming techniques are known (cf. REINECK, 1963a; MaARse and Terwindt, 1964; JiCMulleiv and Allen, 1964; Bouma, 1964a; Bouma and MARShall, 196́s). If different mineralogical components are present in the sample radiographic picture can be obtained. A completely pure sediment or a well-crystallized pure vein in a rock will give a blank result. The content of clay against sand in a sediment can still be detected. The technique should be applied mainly for collecting detailed data or additional information on primary and secondary 
structures, and for detecting the presence of structures in deposits that do not show them at first sight.

Only a small number of prints of X-ray radiographs have been published so far (Hamblin, 1962; Calvert and Veevers, 1962; Rioult et Riby, 1963; Oele, 1964; Bouma, 1963, 1964b, c; Bouma and Shepard, 1964; Bouma and Marshall, 1964).

An attempt is made in this paper to describe shortly the technique of making a radiograph. With the help of prints of radiographs (now called radiographs) the present author will discuss the results obtained from sandy and clayey samples with and without fossils or organic remains, collected from three different environments. Material obtained from salt marshes and from submarine canyons has been analysed at the Scripps Institution of Oceanography at La Jolla, California, with a General Electric X-ray unit, while estuarine deposits have been radiographed at the Geological Institute in Utrecht, The Netherlands, with a Philips-Müller Macro B tank.

\section{RADIOGRAPHICAL TECHNIQUES AND PROCESSES}

Radiation that passes an object will be partly absorbed. Practically no sediment sample is absolutely homogeneous; the quantity of radiation that passes the sample therefore varies from spot to spot. When the non-absorbed X-rays fall upon a special film, the photographic film emulsion will also be inituenced differently. The picture obtained in this way gives the scientist a source of information of which is little known at the present time.

The absorption not only depends on the type of particles the radiation passes through, but also on the amount of particles, on which the thickness of the sample depends. The X-rays follow straight paths, which implies that the image obtained is the projection of all absorption and passing-through properties of all sediment particles lying behind each other in the path of the rays. With increasing thickness of the sample more different characteristics of the sample will be projected upon each other. It is also important to use planparallel slices of a sample to avoid differences in blackening of the film owing to sample-thickness variations. A stereographic procedure should be applied to samples with varying thicknesses, such as cores and irregular specimens (see HAMBLIN, 1962; Bouma, in preparation).

In Fig. $1 \mathrm{~B}$ and $1 \mathrm{C}$ the results are demonstrated for the same sample slice with two different thicknesses. The thickness of the planparallel slice in Fig. $1 \mathrm{~B}$ is $20 \mathrm{~mm}$, while this slice was thinned down to $5 \mathrm{~mm}$ before a second radiograph was made (Fig.1C). All characteristics of Fig. 1C can be found in Fig.1B (see the corresponding numbers), but Fig.1B also reveals properties that were present in the upper threequarters that had been removed in order to make Fig.1C. It clearly shows that working with a thin slice yields results that are better to distinguish. One should use a type of film which is contrast-rich. In Fig.1A and B the results are given of both the application of a medical X-ray film and a technical X-ray film. In both cases the same sediment slice was used and all working conditions were the same, except for the 
exposure time. The result is quite obvious. All sediment properiies visible in Fig. IA can be found in Fig. IB (see corresponding numbers), but the latter one gives much more contrast and makes an interpretation easier. Only some details in plant fragments (point 1) can be better observed by using a medical film (see further below).

The present author tried out several types of films from different manufacturers. The other examples given in this contribution are obtained by using Kodak Industrial film type AA. This film is fairly fast and the granularity makes it possible to obtain good contact prints or small enlargements.

As radioactive source a small $X$-ray unit can be used which has a maximum voltage of about $100 \mathrm{kV}$. Increasing voltage does not change the wave lengths of the emittant spectra, but only adds short wave lengths to it. The penetration power and amount of radiation then increase, but so does the scattering. The result is a decrease in clearness of the image, especially for voltages over $150 \mathrm{kV}$. It is recommended to work with a unit whose tube current is not too high and too variable (for example, from 0 to 4 or $15 \mathrm{~mA}$ ). The amount of radiation to which a specimen is exposed is the product of tube current and exposure for a certain $\mathrm{kV}$. A low $\mathrm{mA}$ implies a longer exposure time, which is not of importance in our field. The present author worked with a General Electric Mobile "90-11" X-ray unit set at $40 \mathrm{kV}$ and $5 \mathrm{~mA}$ or $90 \mathrm{kV}$ and $15 \mathrm{~mA}$, as well as with a Philips-Müller Macro B tank (40-100 kV, 0-4 mA).

The distance between the X-ray source and the object should not be too short so as to assure the object's being covered completely by the X-ray beam. Irradiation of exposure increases squarely with a linear increase of distance. As distance between the X-ray source and the object-film unit a length of 38 inches or about $1 \mathrm{~m}$ is advisable.

The technique itself is very easy to apply. Care should be taken with the protection rules against radiation as given by the authorities in each country. Regular medical checks are important. If possible the control panel of the X-ray unit should be in a room adjoining the one where the $\mathrm{X}$-ray tube is found. The wall between both rooms must be covered with enough lead that the radiation still passing is less than the dose that is allowed for human beings. Often both parts of the X-ray unit are placed in one room with a lead screen in between. In such a case the whole room must be covered with lead to avoid reflection of radiation. In this situation it is far more difficult to protect those persons involved against radiation.

Everyone wanting to work with this technique should read some basic information on it; several companies that manufacture $X$-ray films supply this information (for example Anonymous, 1957, 1962a, 1962b).

Fig.1. Prints of radiographs made from clayey salt marsh sediments. For all three photos the same sample slice has been used. The thickness of the slice is $20 \mathrm{~mm}$ for Fig.1A, B; for Fig.1C the upper $3 / 4$ have been removed. Point 33 : roots of Salicornia; point 34; stem of Spartina; point 26: concretions of iron oxide. For further explanation see text. Mission Bay, San Diego, California, U.S.A. A: medical film, $90 \mathrm{kV}, 15 \mathrm{~mA}, 2 \mathrm{sec}$. B: industrial film, $40 \mathrm{kV}, 5 \mathrm{~mA}, 160 \mathrm{sec}$. C: industrial film, $40 \mathrm{kV}$, $5 \mathrm{~mA}, 45 \mathrm{sec}$. 


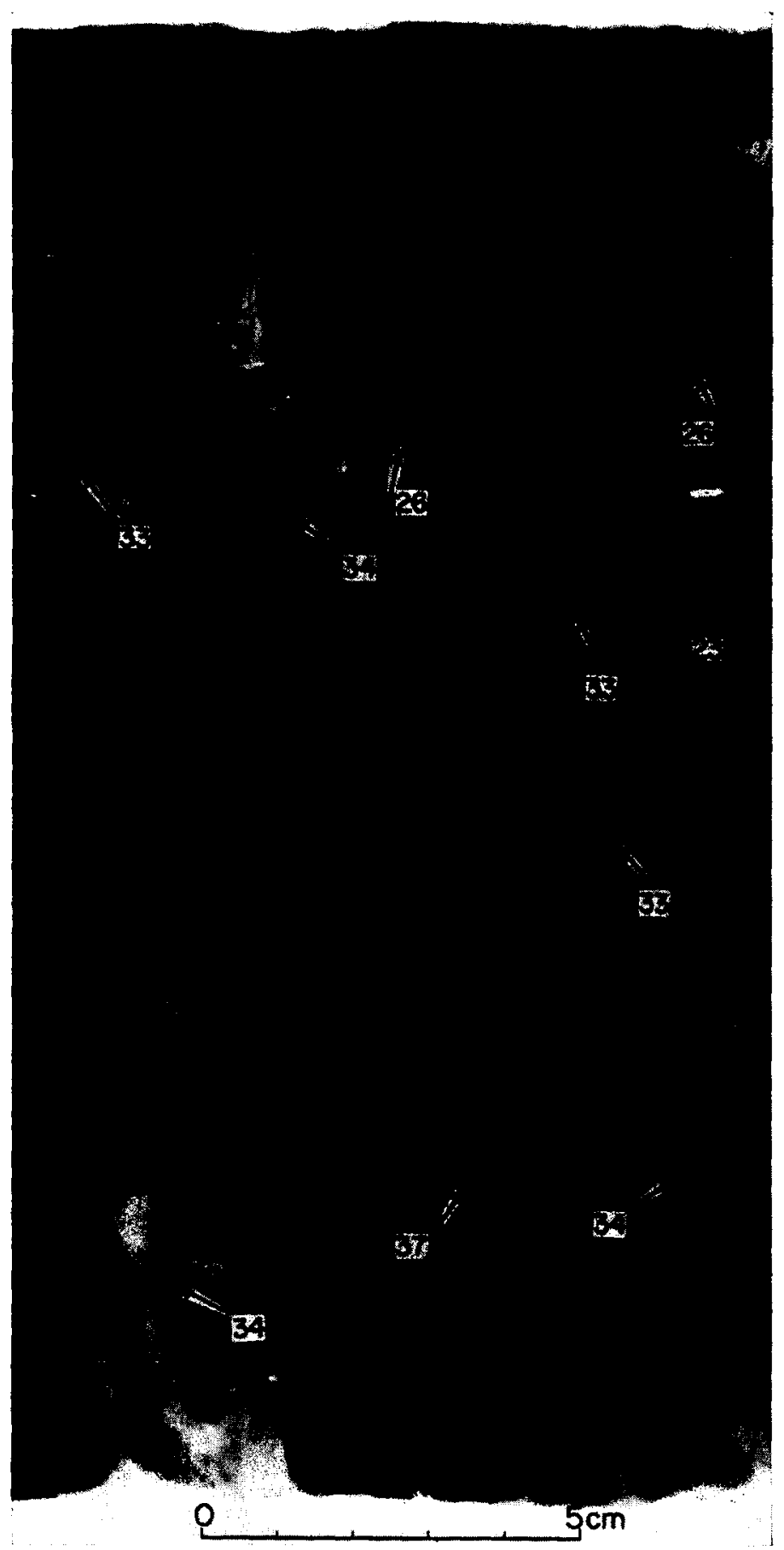

Fig.1A (Legend see p.280).

Marine Geol., 2 (1964) 278-309 
A. H. BOUMA

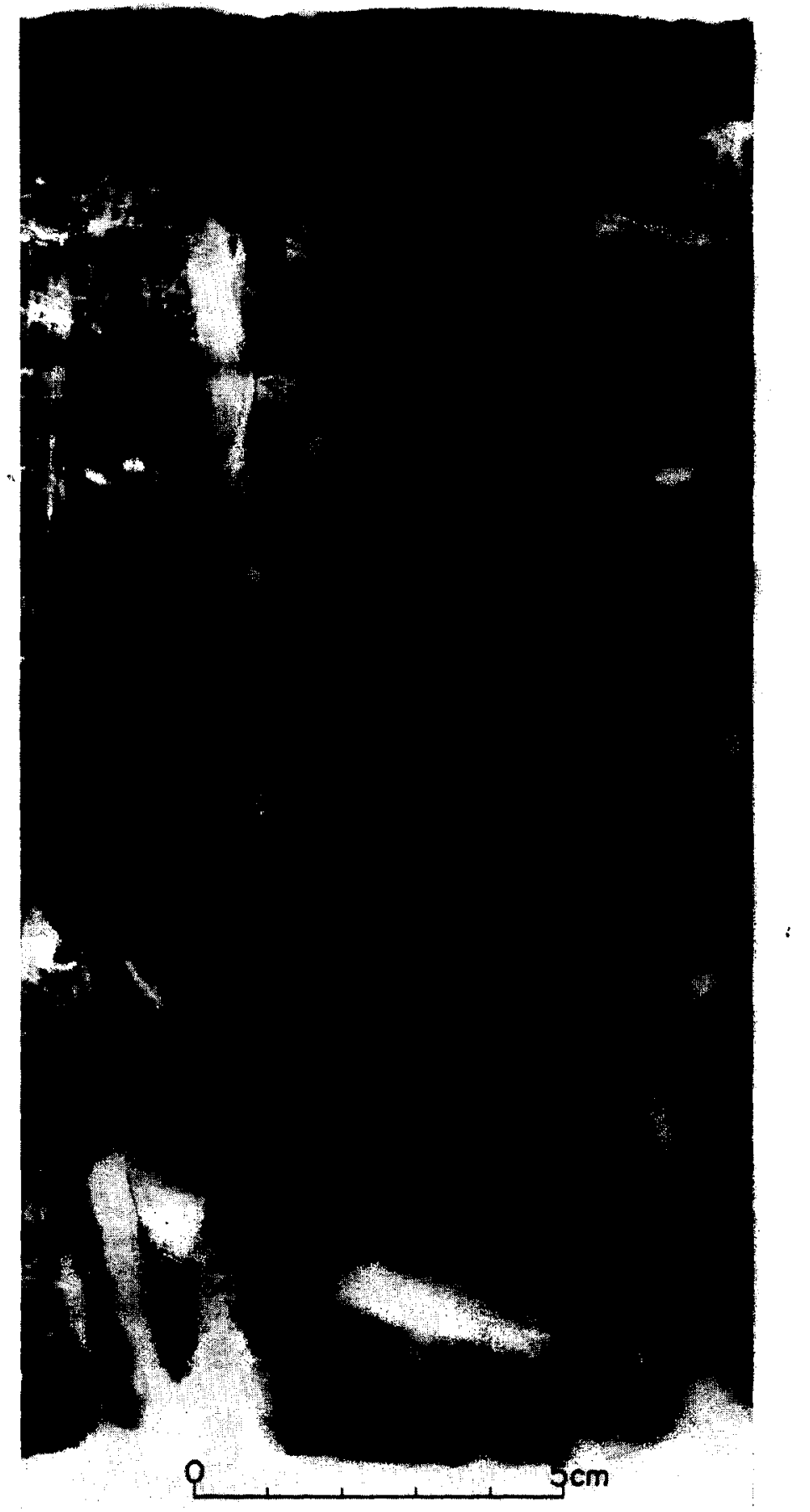

Fig.1B. (Legend see p.280.) 


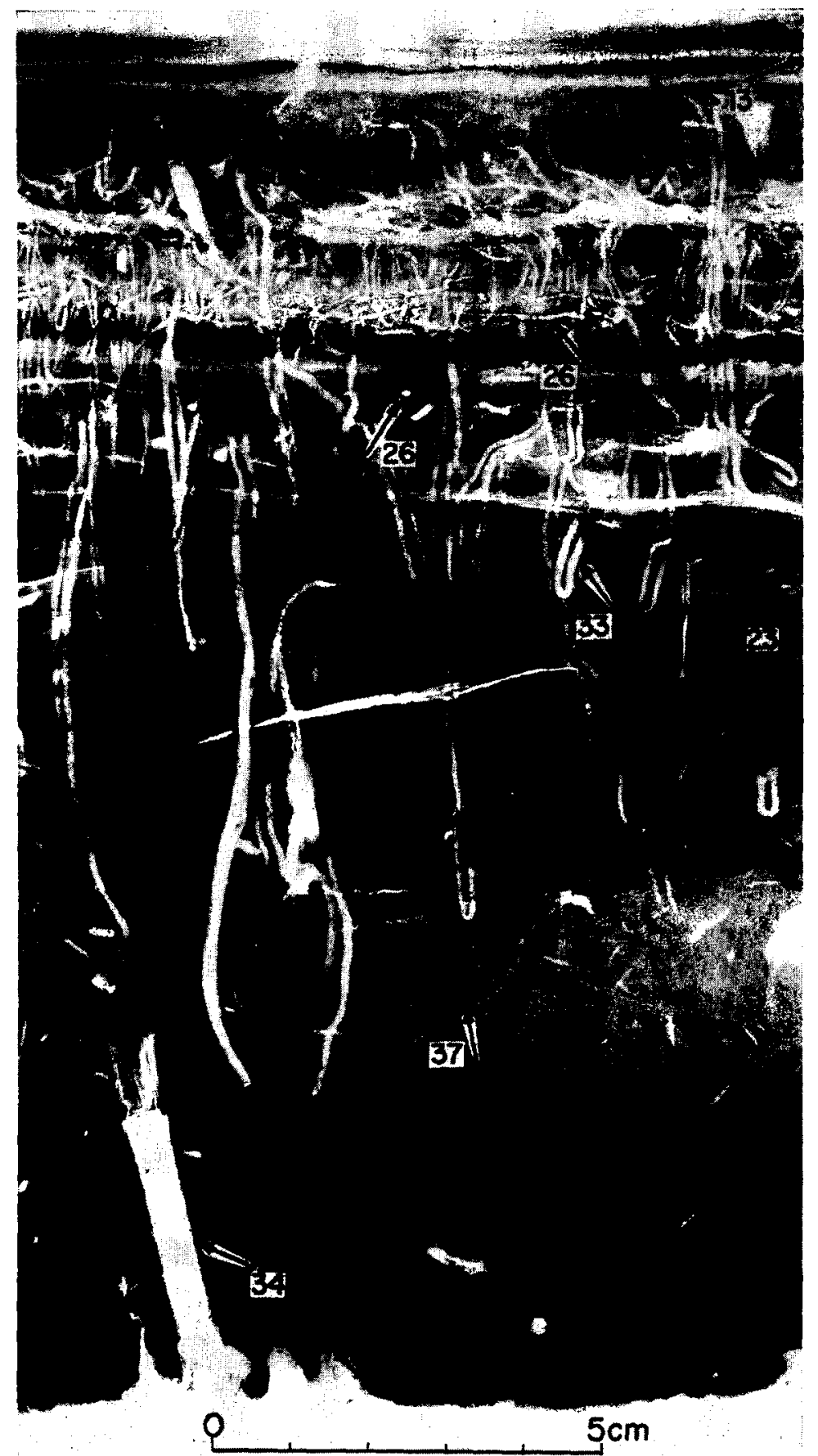

Fig.1C. (Legend see p.280.) 
Unconsolidated sediments can be sliced with a wire or cheese cutter (CALVERT and VeEvers, 1962; Bouma and Marshall, 1964). A wet, strong, steel plate with a sharpened edge should be pushed behind the wire. It is better to start with a thick slice (2-5 cm, depending on the type of sediment and size of the sample) and to thin this down with a spatula or a knife, in order to prevent folding during the slicing operations.

The slice can be put onto a thick celluloid, plexiglas or plastic plate. All these types of materials are isotropic to X-rays and do not give an image. A film sheet is put into its holder or cassette and the slice is now moved carefully onto this holder. Lead numbers, letters and arrows should also be placed on the cassette in order to get directly the sample number and other data in the film (see Fig.3, 17). This whole is now placed directly under the X-ray tube in horizontal position and can be radiated.

After the exposure the sample, lead numbers, letters and arrow are removed from the cassette, and the film can be developed in a special bath. The obtained negative can be studied directly or a print can be made of it. Just as in normal photography the investigator should realize that dark and light parts of the negative become light and dark respectively on the print. Parts of the sample with a low absorption co-efficient to radiation, such as plant fragments and clay, become dark on the negative and thus light on the print. X-ray negatives are sometimes very contrast-rich which makes it difficult to make prints. Special methods should be used such as the application of super-proportional reducers to lighten the darkest parts of the negative, or several prints with different exposure times can be made which later will be mounted together as a mosaic (Bouma, in preparation).

It was found that equal results can be obtained from consolidated as well as from unconsolidated sediments. The unconsolidated ones may be dry, moist or wet: they may be impregnated with a synthetic material or imbedded in plastic or plexiglas. The presence of water or similar material does not influence the image; it only needs a little longer exposure time.

\section{INTERPRETATION OF X-RAY RADIOGRAPHS}

\section{Operational failures and mistakes (points 1-15 in the figures)}

Often there are a number of dark and light shapes visible on the radiograph which are not due to the sedimentary content of the sample. The interpretation may be difficult since there are always figurations which are unknown to the observer. An attempt is made here to point out on prints those figures which the present author thinks are operational mistakes.

\section{White straight or irregular lines}

These are cracks made during slicing operations or when moving the slice onto the exposure holder. It is very easy to eliminate their presence from the surface with 


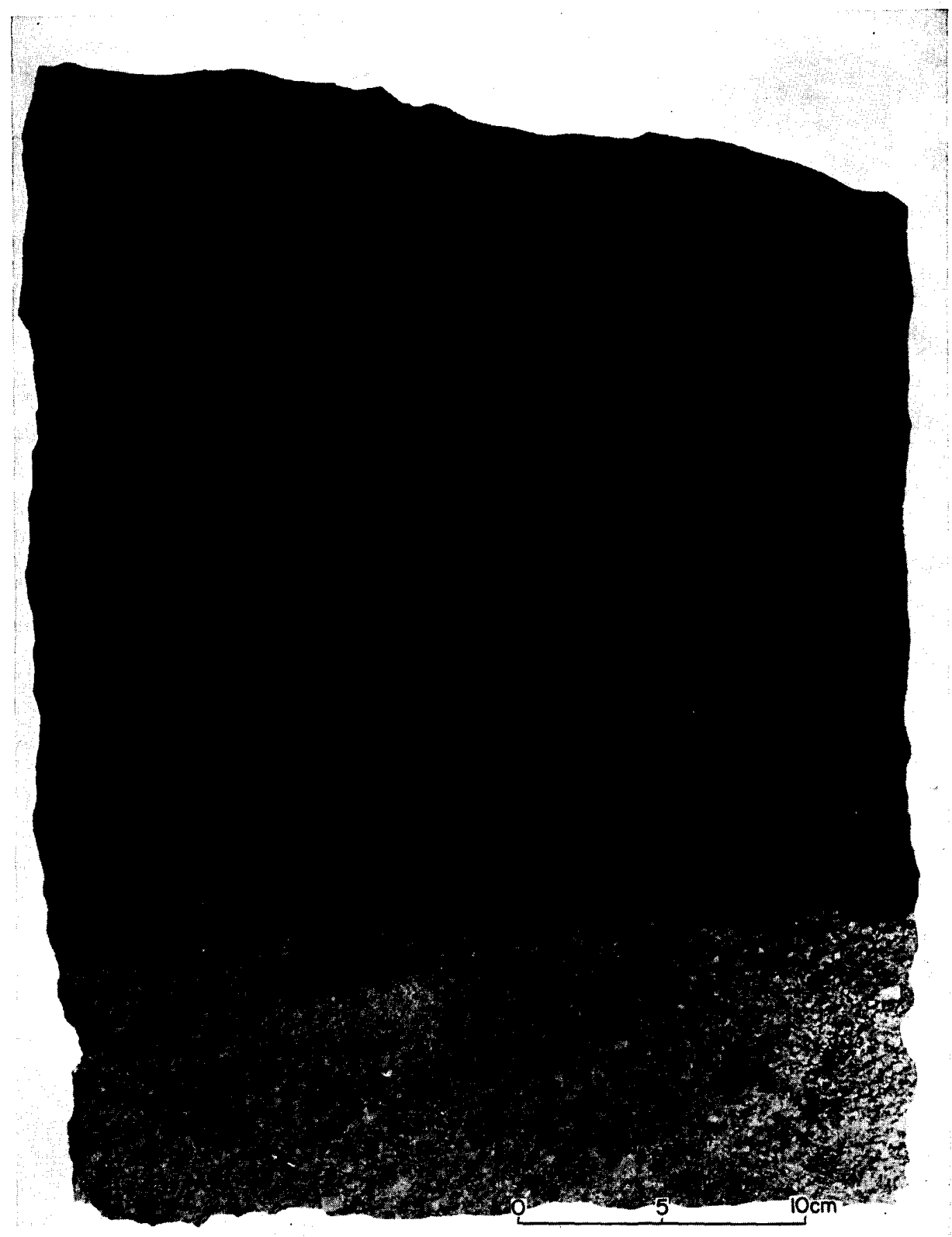

Fig.2. Photograph of a vertical slice of sample SJ-17, collected in the axis of Santa Maria Canyon at a depth of 368 fathoms. Lower part consists of ungraded gravel and coarse sand of unweathered granitic material. The upper part is a clayey sand. Baja California, Mexico.

Marine Geol., 2 (1964) 278-309 


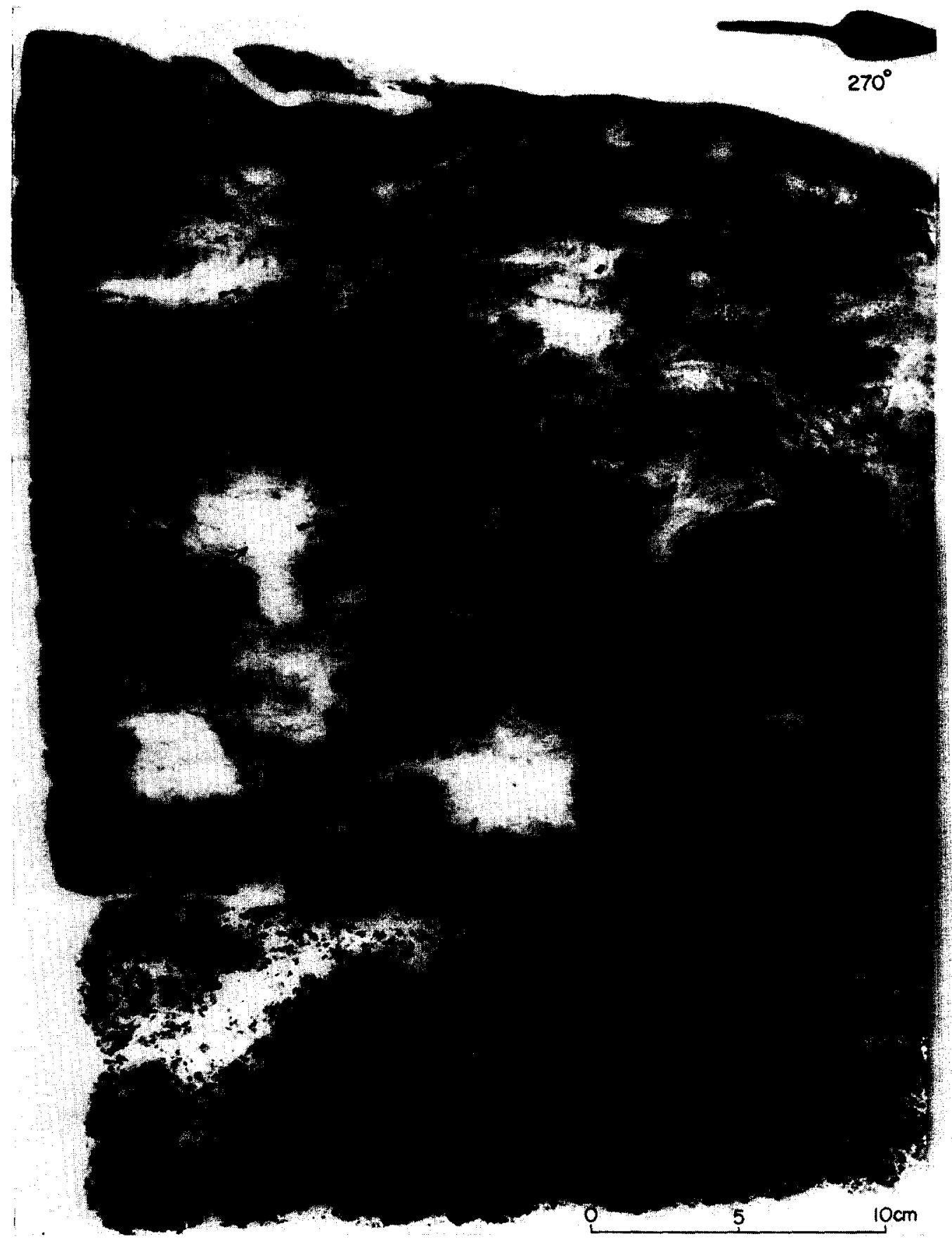

Fig.3. Print of a radiograph made of the slice given in Fig.2. Upper part is disturbed by slumping and burrowing. Point 28 is a gastropode. For further explanation see text. Thickness of lower part of the slice 12-18 mm; upper part $12 \mathrm{~mm}$. Industrial film, $40 \mathrm{kV}, 5 \mathrm{~mA}, 3 \mathrm{~min}$. 
a knife or a spatula before taking a photograph, but they cannot be hidden to the X-ray bundle (compare Fig.2 and 3, 6 and 7, 8 and 9, point 1; see Fig.10 and 11, point 1; Fig.12 and 13, 14 and 15, point 2).

To this group also belong the wedge-shaped cracks that are sometimes formed at the top of a sample due to drying out. These cracks have been filled up later with a gel to prevent additional forming of cracks (cf. Bouma and Marshall, 1964). They are slightly masked in the normal picture (Fig.4, point 3), but since the gel is isotropic to the radiation the crack is clearly visible in the radiograph (Fig.5, point 3).

Sometimes cracks are visible on the photographs which cannot be observed in the radiograph (compare Fig.12 and 13; Fig.14 and 15, point 4). In such cases photographs were taken later to allow the slice to dry out a little in order to obtain more contrast at the surface (Fig.14), or to be able to make a lacquer peel (Fig.12; BOUMA and MARSHALL, 1964).

\section{Light-coloured spots}

They may be caused by thin parts or holes in the slice (Fig.8, 9, point 5). These parts allow too much radiation to pass compared with the rest of the sample. Irregular light-coloured spots visible in Fig.3 (point 6) cannot directly be explained in this way. Their origin is unknown.

\section{Cracks, scratches, rims and non-sedimentary patterns at the slide surface}

The slicing movements must be made parallel to the main bedding of a sample to avoid breaking along bedding planes. It is difficult to avoid small shallow cracks and scratches (Fig. 4, 8, 18, point 7), and rims on both ends of the knife during slicing (Fig.4, 6, 8, 18, point 8). These rims often give the impression of false bedding.

The irregular dark patterns visible on the slice are due to reduction at places where the covering thin plastic foil (Saran wrap to prevent drying out during storage in a refrigerator) touched the surface (Fig.6, 8, 18, point 9).

Sand grains which are rolled over the surface with the knife may produce small pits with or without scratches (Fig.18, point 10). In the same figure (point 11) another misleading pattern is visible. This rhombic-formed pattern is the imprint of a masonite plate placed on top. This plate may fold the covering plastic foil in some places and the imprints may give difficulties in interpreting lines (Fig.6, 8, 16, 18, point 12).

All these small irregularities at the surface of a slice do not give any image on the radiograph.

\section{Dry spots, dust and damages on the radiograph}

There are always possibilities of damaging the X-ray negatives. Especially wet negatives should be handled carefully, also in the special developing tanks, when more than one is developed simultaneously.

Sharp lines are scratches on the negatives (Fig.1C, 6, 7, 9, 16, point 13); 


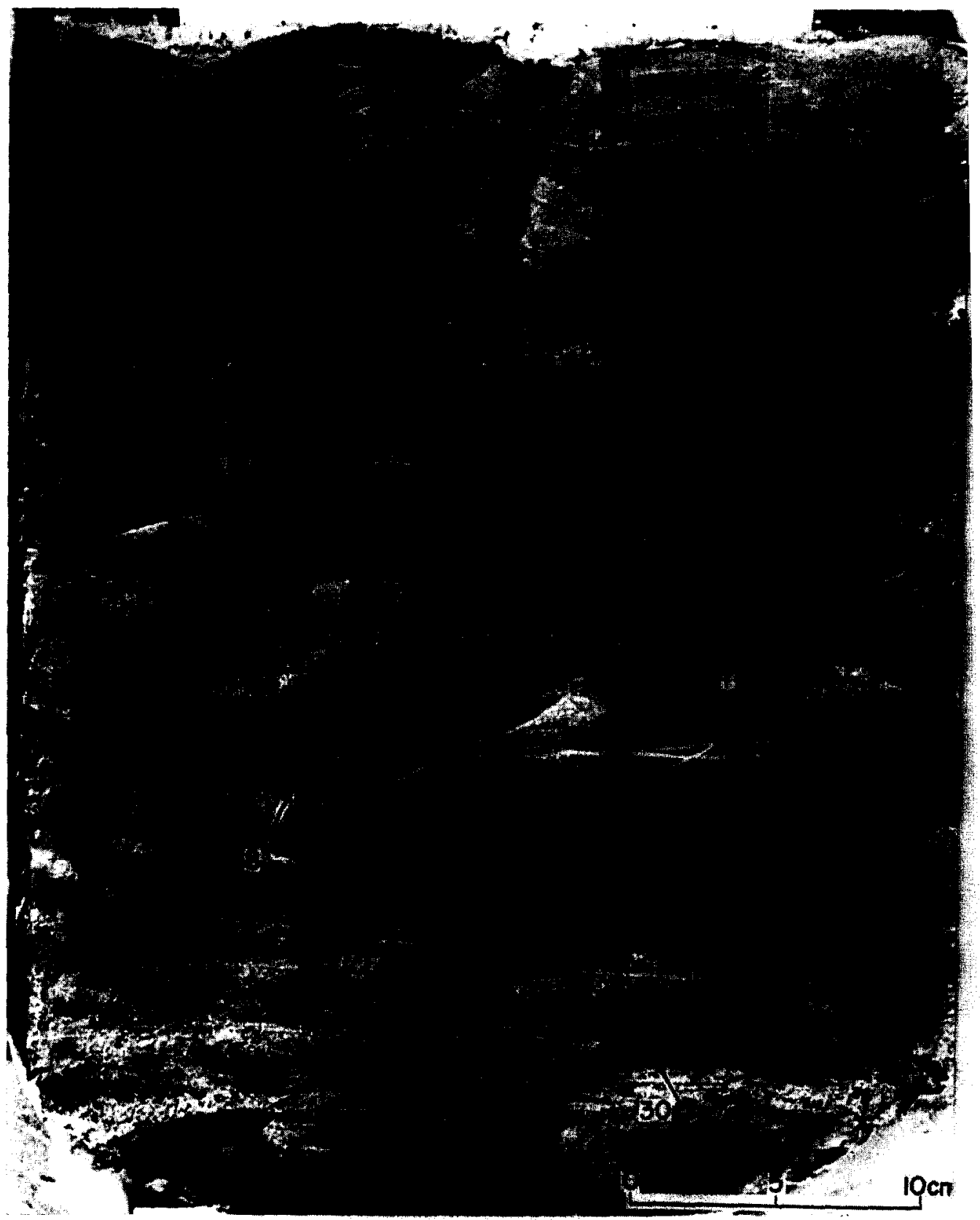

Fig.4. Photograph of a vertical slice of sample SJ-45, collected just north of the northern levee of a small gully in a flat-floored basin in the middle of the Gulf of California, north of a seamount, at a depth of 1,416 fathoms. Sand content decreases upward. Point 30 is a wood rest. Mexico. 


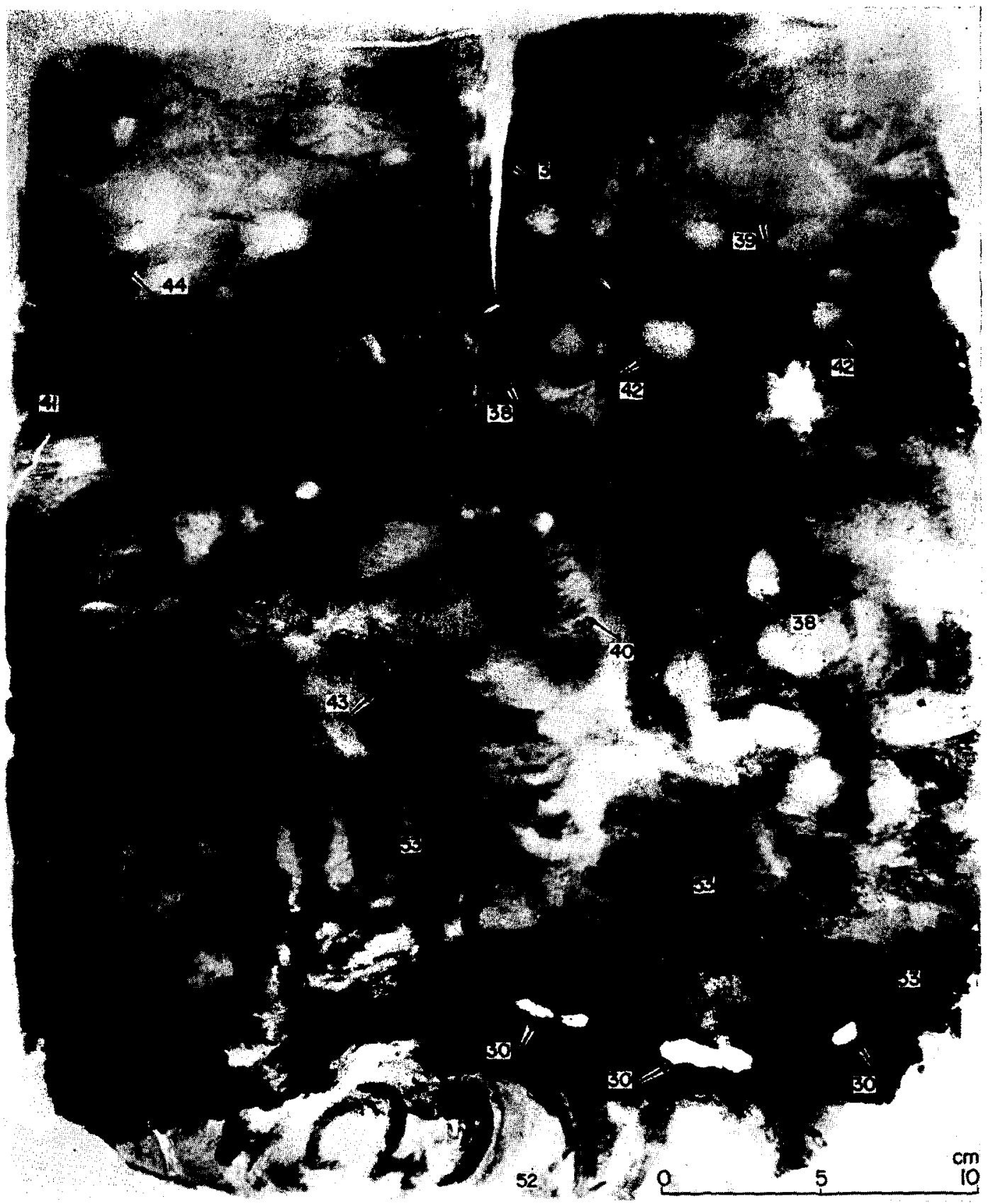

Fig.5. Print of a radiograph made of the slice given in Fig.4. Point 52: slump ball; point 30: wood rests; point 53: slumps ?; other points: types of burrows. Slice thickness: $12 \mathrm{~mm}$. Industrial film, $40 \mathrm{kV}, 5 \mathrm{~mA}, 2 \mathrm{~min}$. 


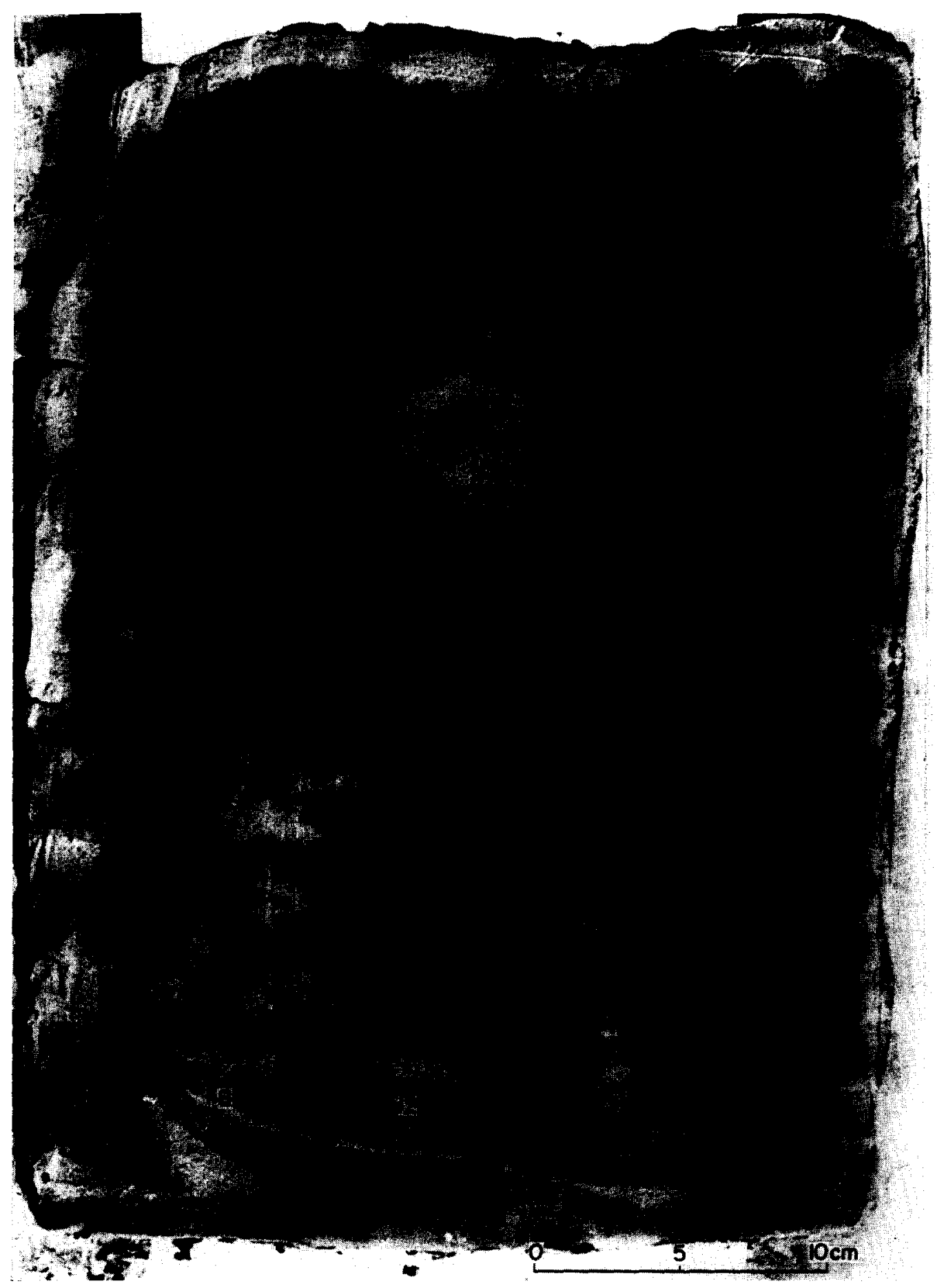

Fig.6. Photograph of a vertical slice of sample LC VI-I, collected from the northern shelf rim of the La Jolla Canyon, California, U.S.A., at a depth of 316 fathoms. The black colour is due to reduction at places where covering plastic foil touched the surface. 


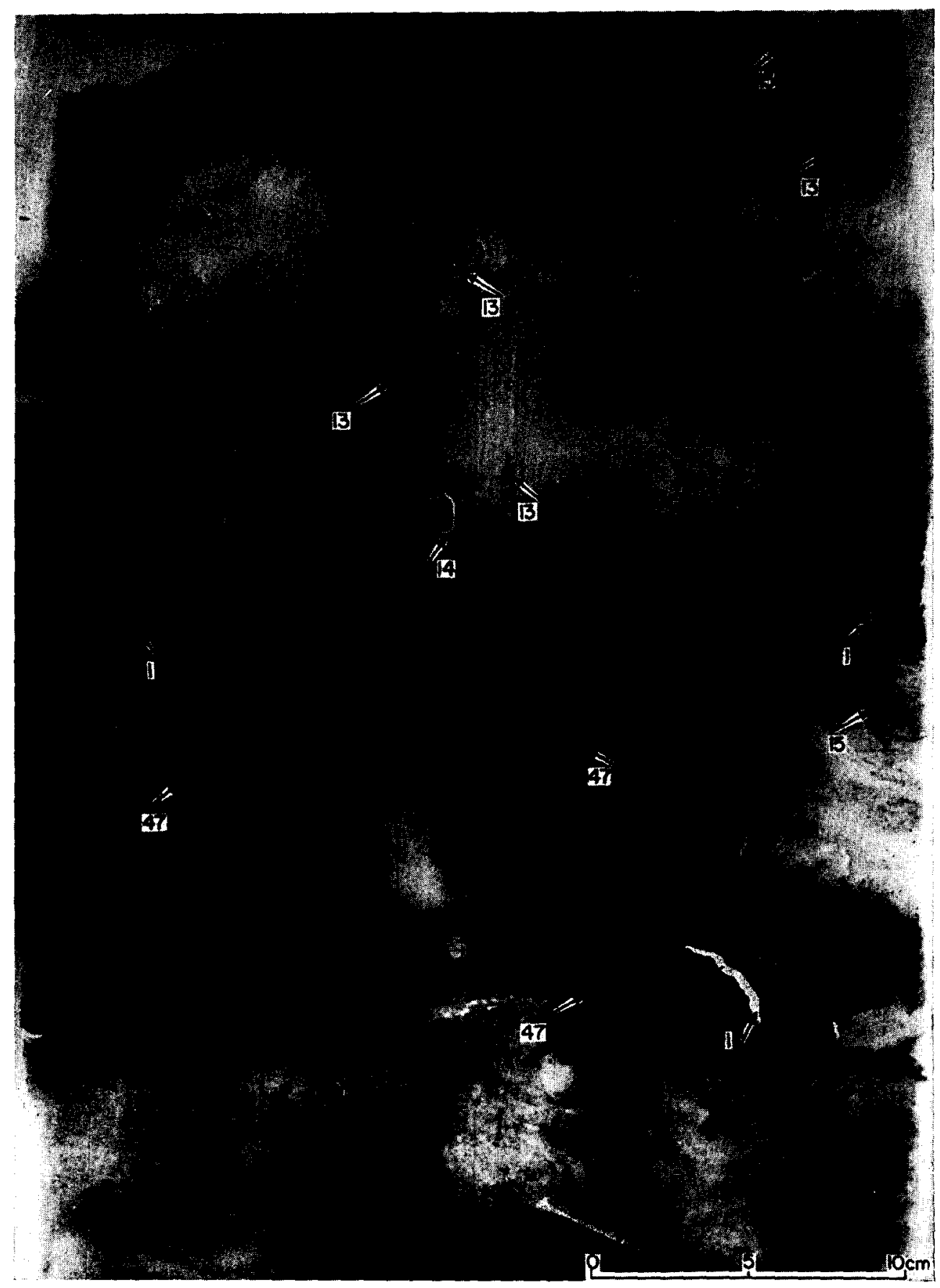

Fig.7. Print of a radiograph made of the slice given in Fig.6. The dark coloured areas are silty lumps, displaced by slumping. For further explanation see text. Slice thickness $12 \mathrm{~mm}$. Industrial film, $40 \mathrm{kV}$, $5 \mathrm{~mA}, 2 \mathrm{~min}$. 


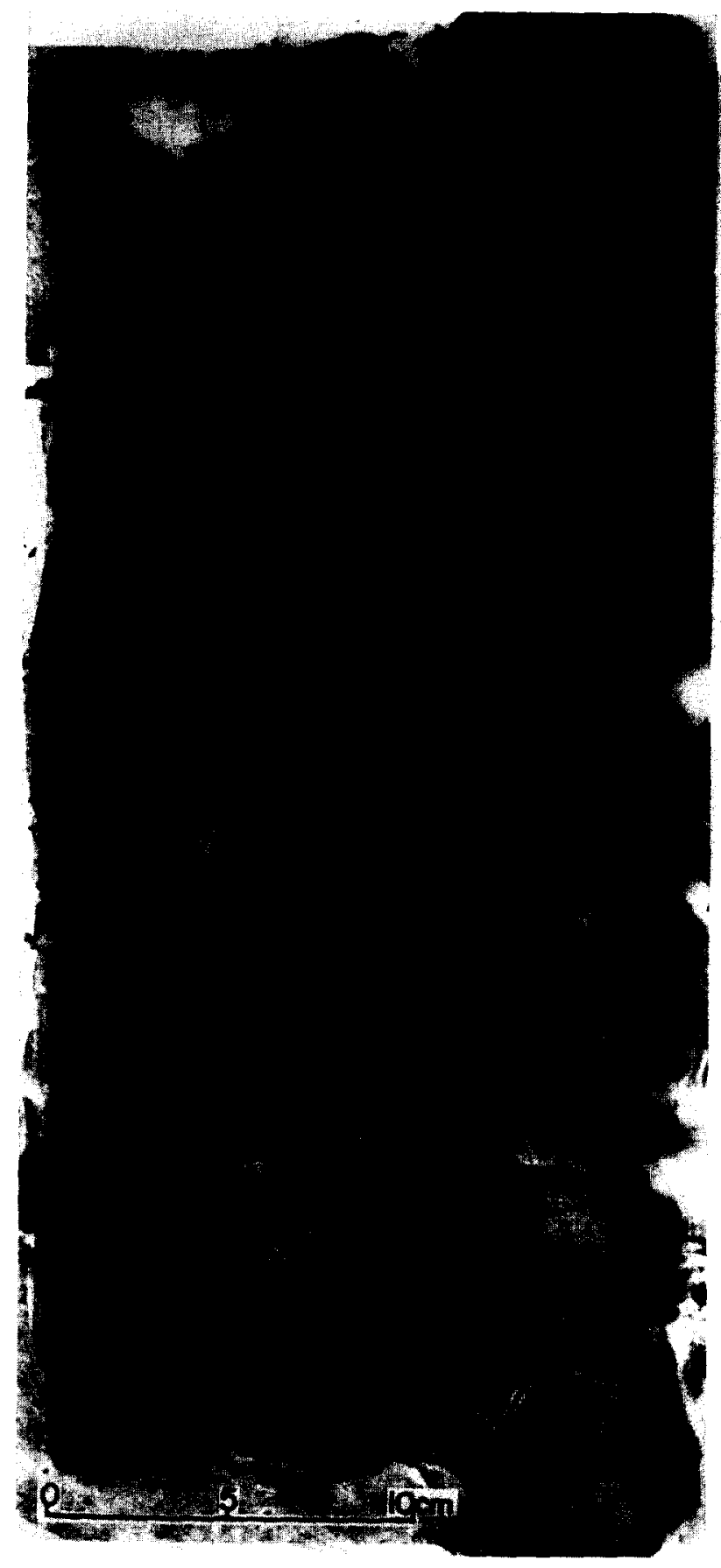

Fig.8. Photograph of a vertical slice of sample LC V-12, collected near the axis of the Coronado Fan Valley, northwest Mexico, at a depth of 670 fathoms. The black colour is due to later reduction under a covering plastic foil. The material is a silty clay. 


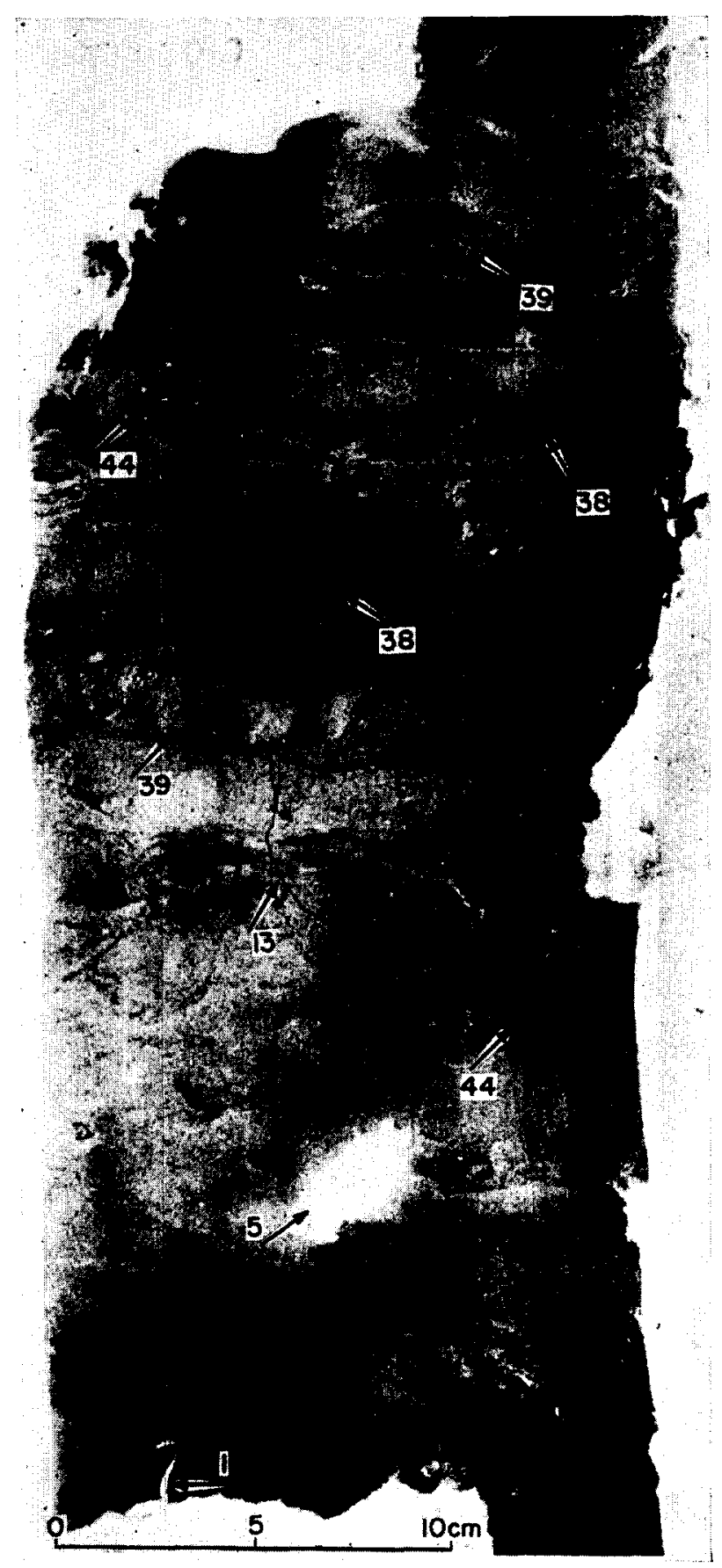

Fig.9. Print of a radiograph made of the slice given in Fig.8. The main characters visible are different types of burrows. Slice thickness $12 \mathrm{~mm}$. Industrial film, $40 \mathrm{kV}, 5 \mathrm{~mA}, 2 \mathrm{~min}$. 


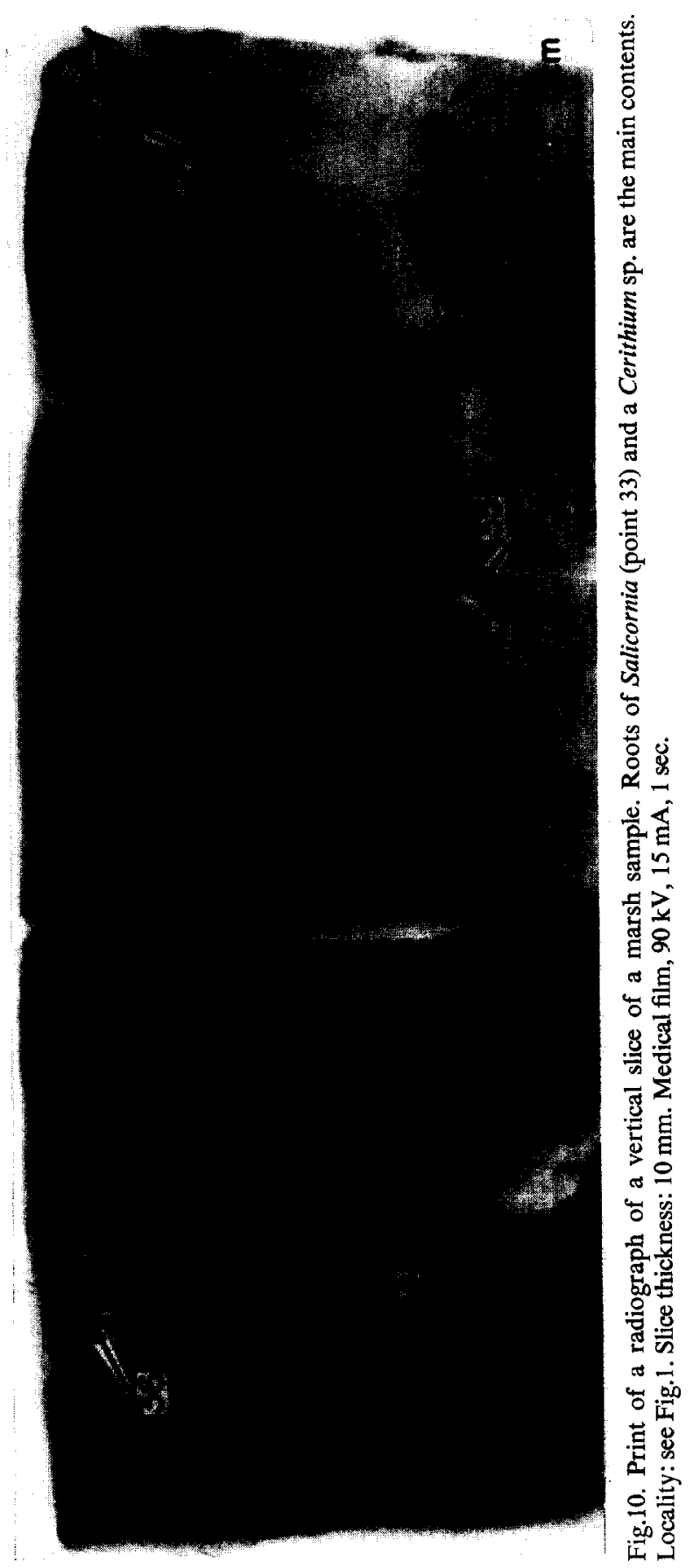

Marine Geol., 2 (1964) 278-309 


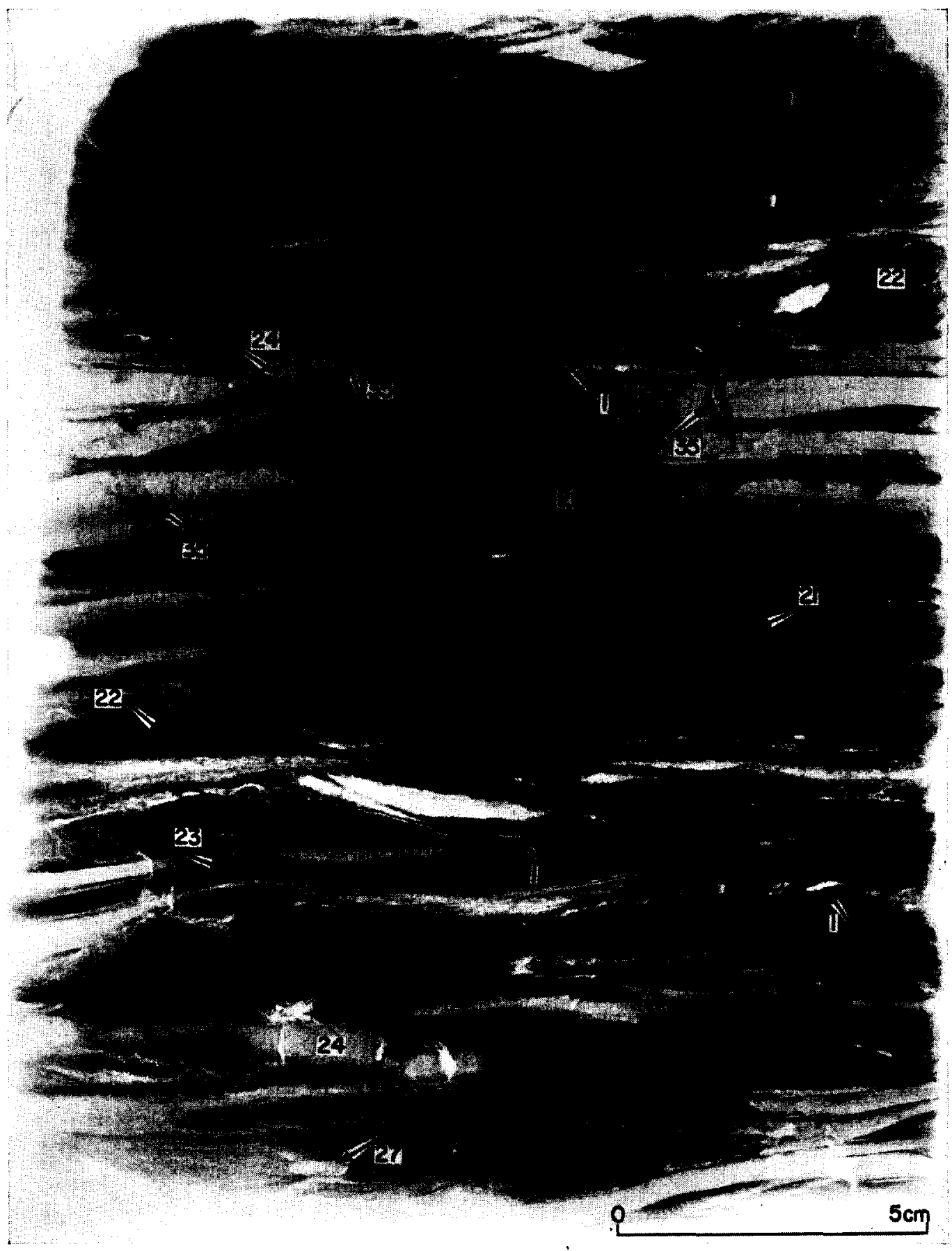

Fig.11. Print of a radiograph of a vertical slice of an estuarine deposit (upper channel fillings). Point 22: sand with fore-set bedding; point 21: clay with sand streaks; point 24: clay. Excavation in the Haringvliet, Delta Project, The Netherlands. 
A. H. BOUMA

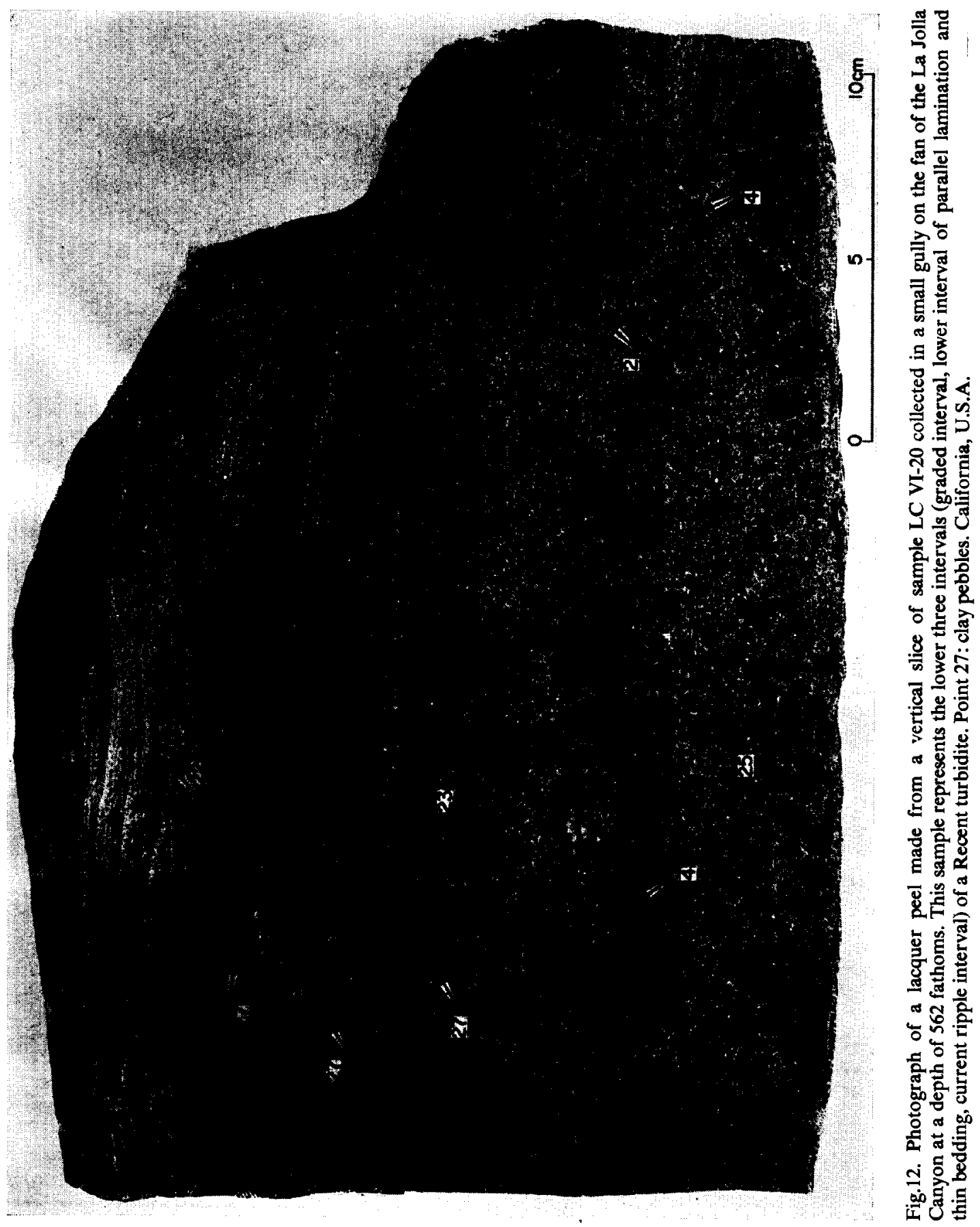




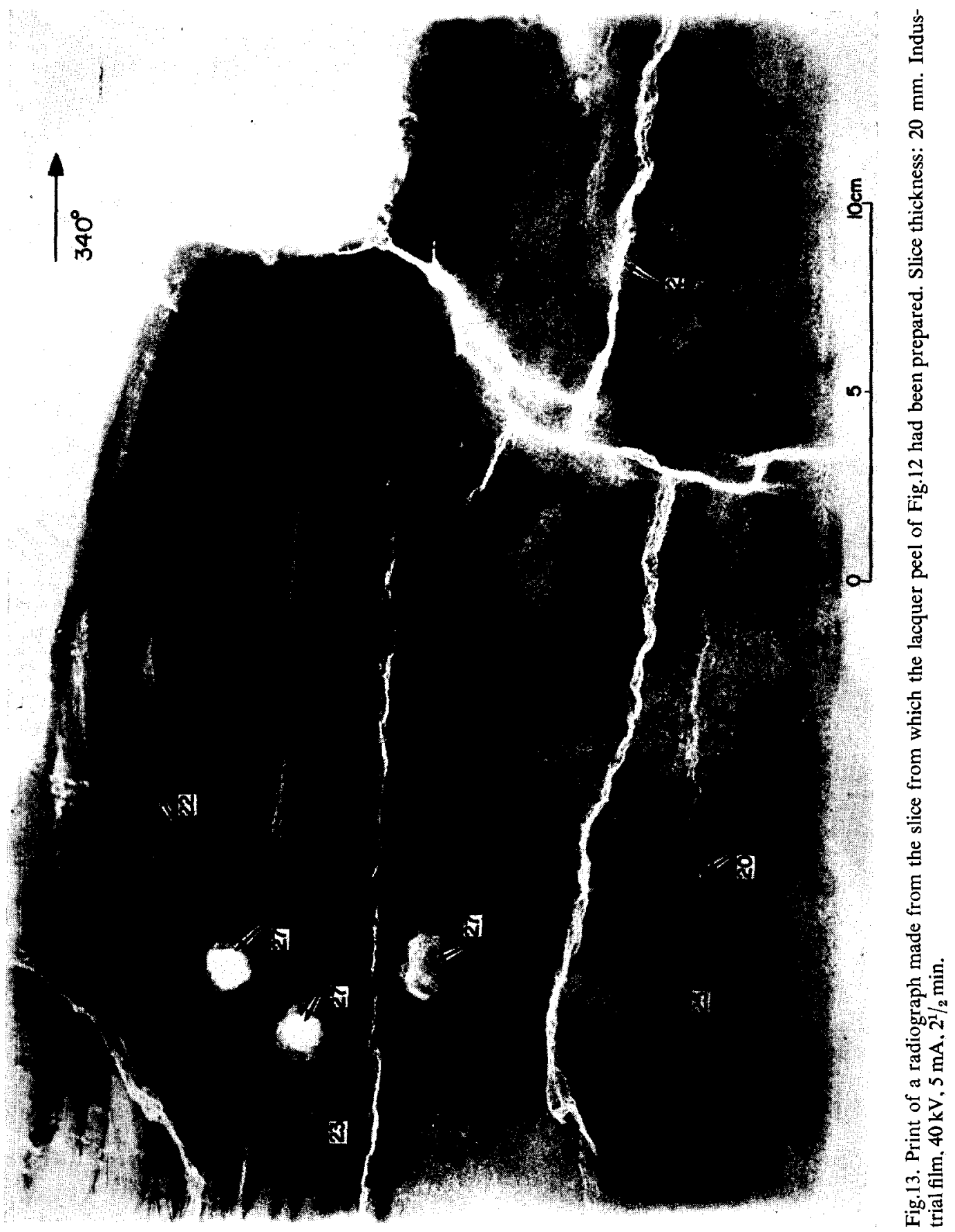




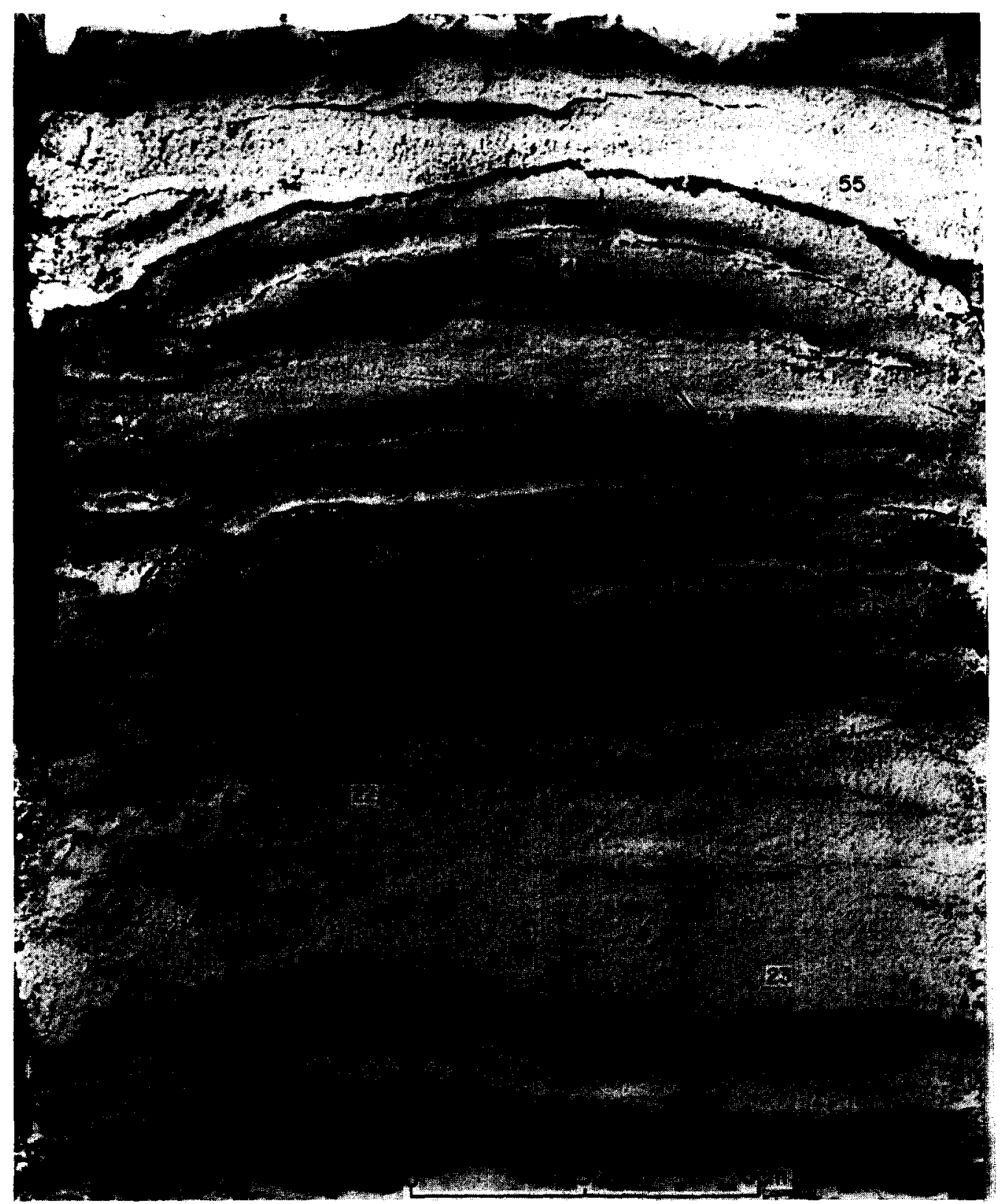

Fig.14. Photograph of a vertical slice of sample LC VI-3 collected from the axial part of the La Jolla Channel at a depth of 362 fathoms. The cracks are due to drying out. California, U.S.A. 


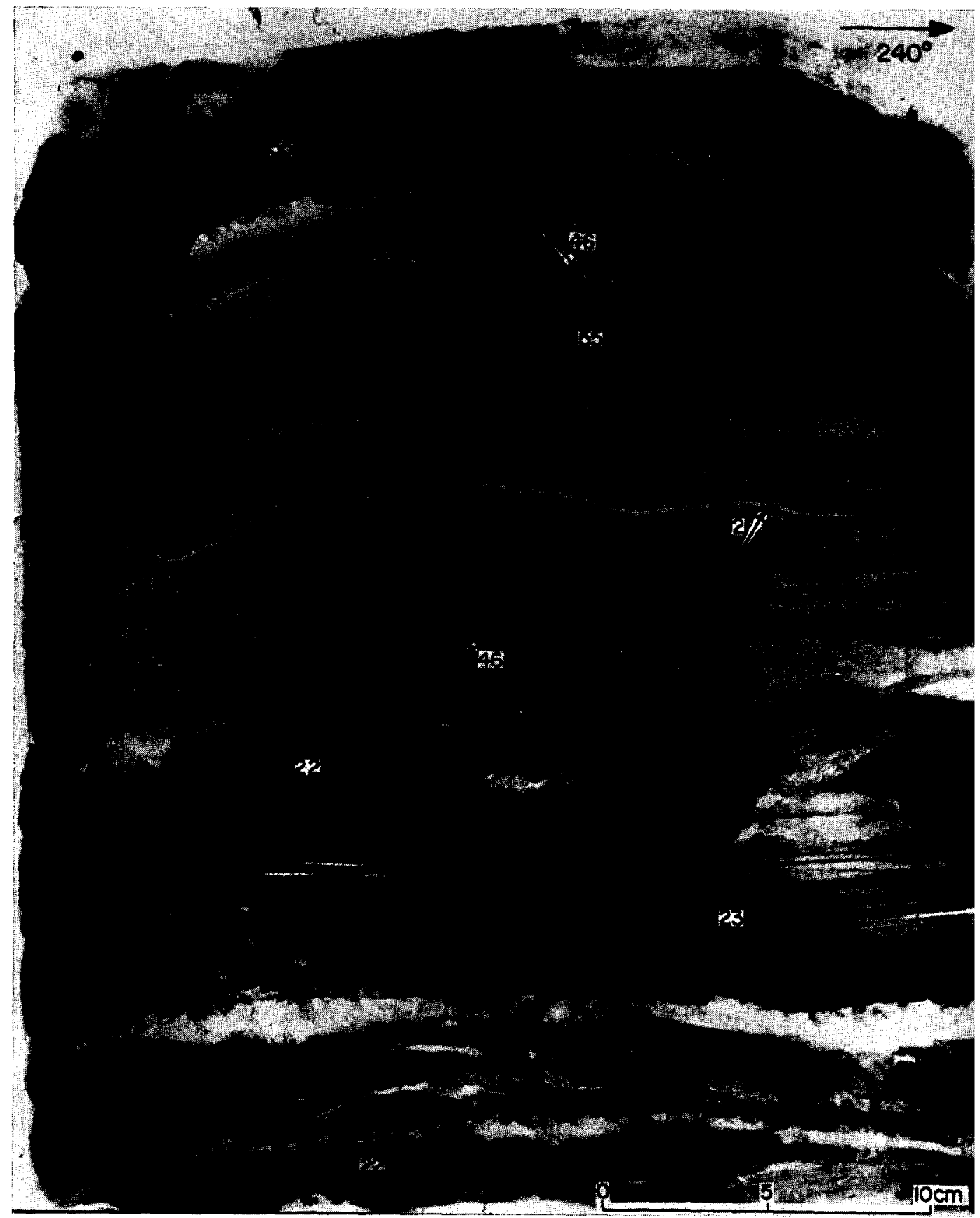

Fig.15. Print of a radiograph made from the slice given in Fig.14. The dark colour represents sandy parts, the light colour shows the clay. Slice thickness $20 \mathrm{~mm}$. Industrial film, $40 \mathrm{kV}, 5 \mathrm{~mA}, 2^{1} / 2 \mathrm{~min}$. 


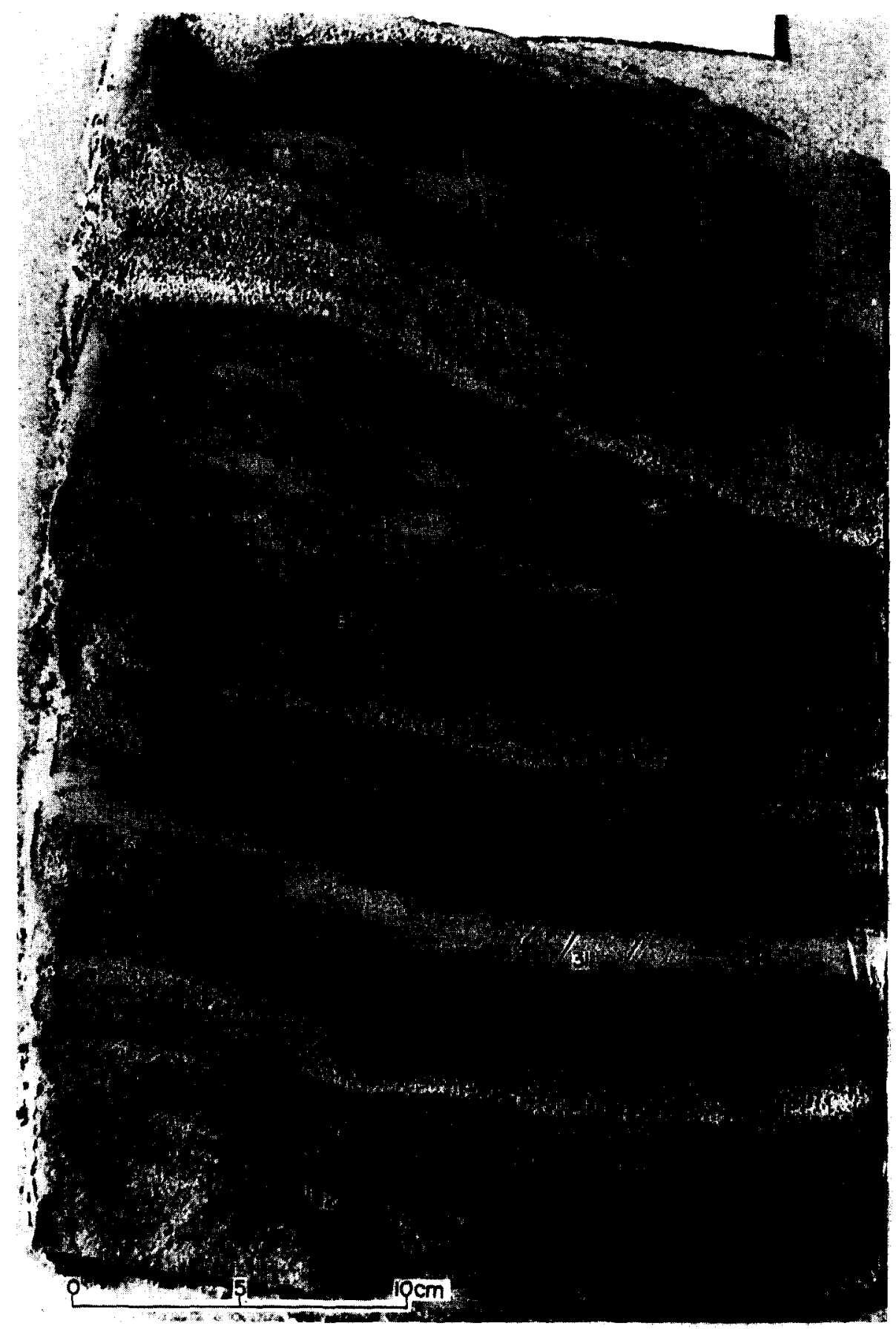

Fig.16. Photograph of a vertical slice of sample SJ-18 collected near the axis of the Santa Maria Canyon at a depth of 183 fathoms. The sample is irregularly bedded with an increasing slope upwards. Baja California, Mexico. 


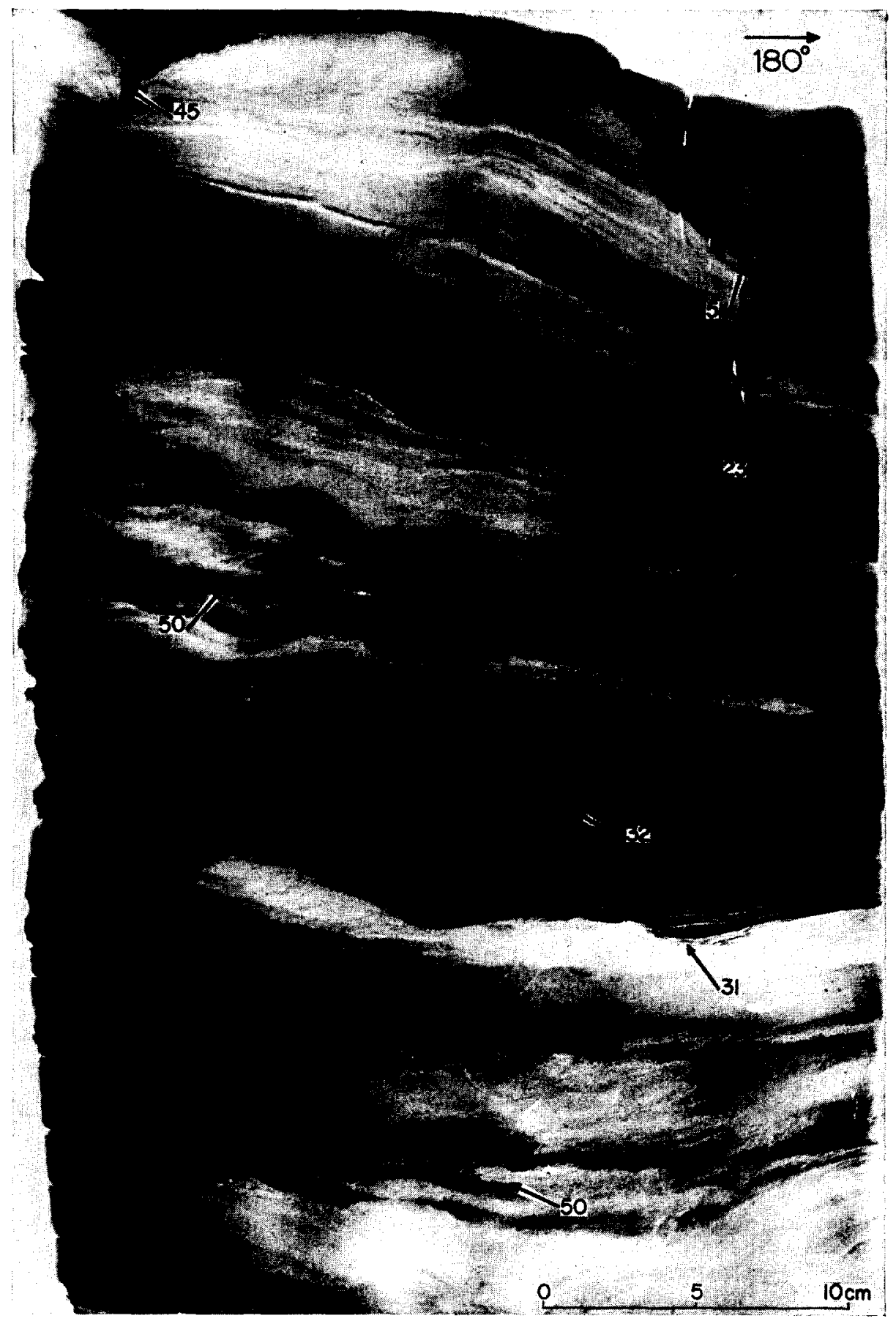

Fig.17. Print of a radiograph made from the slice given in Fig.16. Note the erosional contact at point 31 and the fault at point 51 . Near point 50 results of slumping are visible. Slice thickness $12 \mathrm{~mm}$. Industrial film, $40 \mathrm{kV}, 5 \mathrm{~mA}, 2 \mathrm{~min}$. 


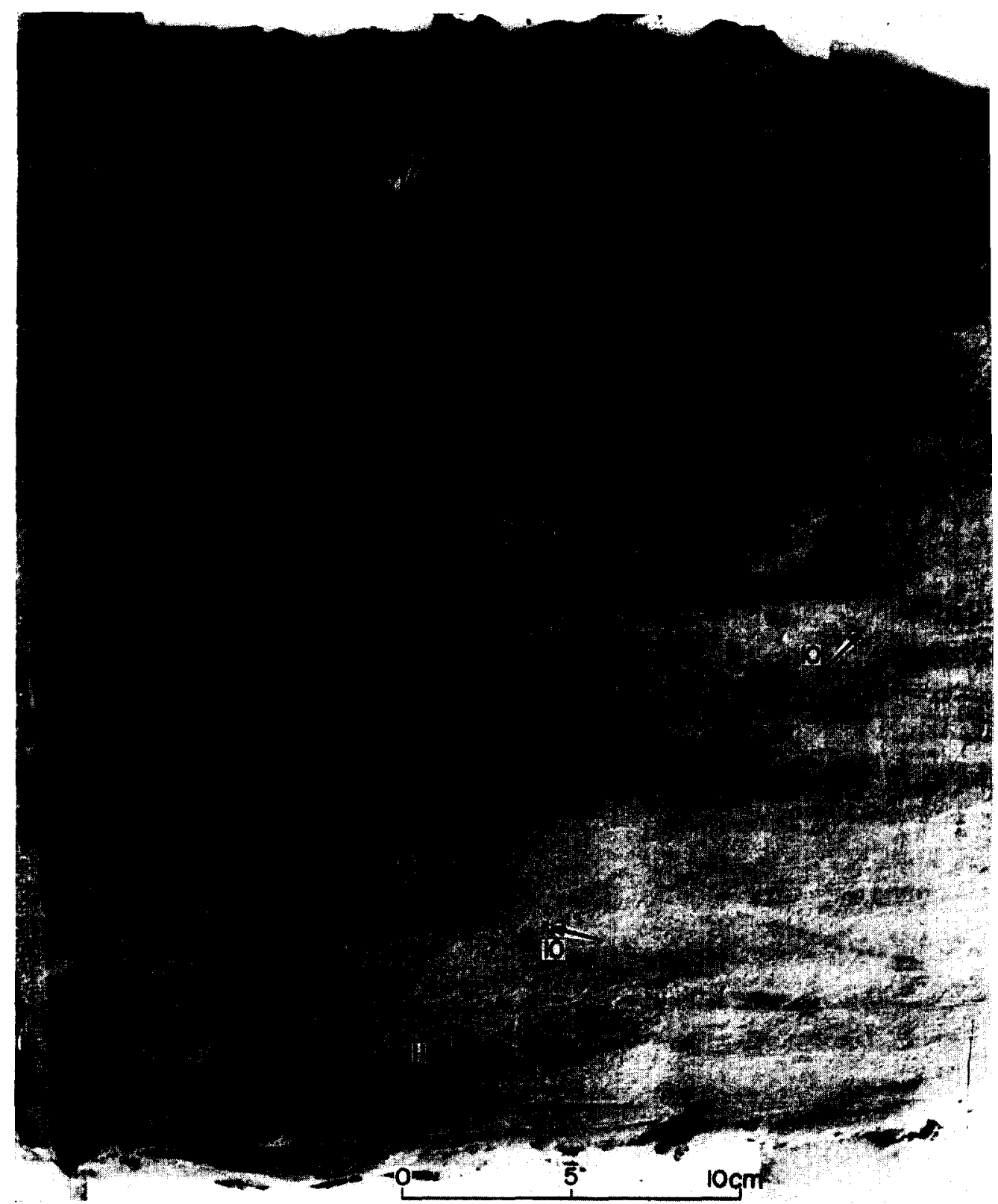

Fig.18. Photograph of a vertical slice of sample LC VI-16 collected from a terrace in the La Jolla Channel at a depth of 310 fathoms. The sediment is a dark green-coloured clay with little silt and mica and a few sand grains. 


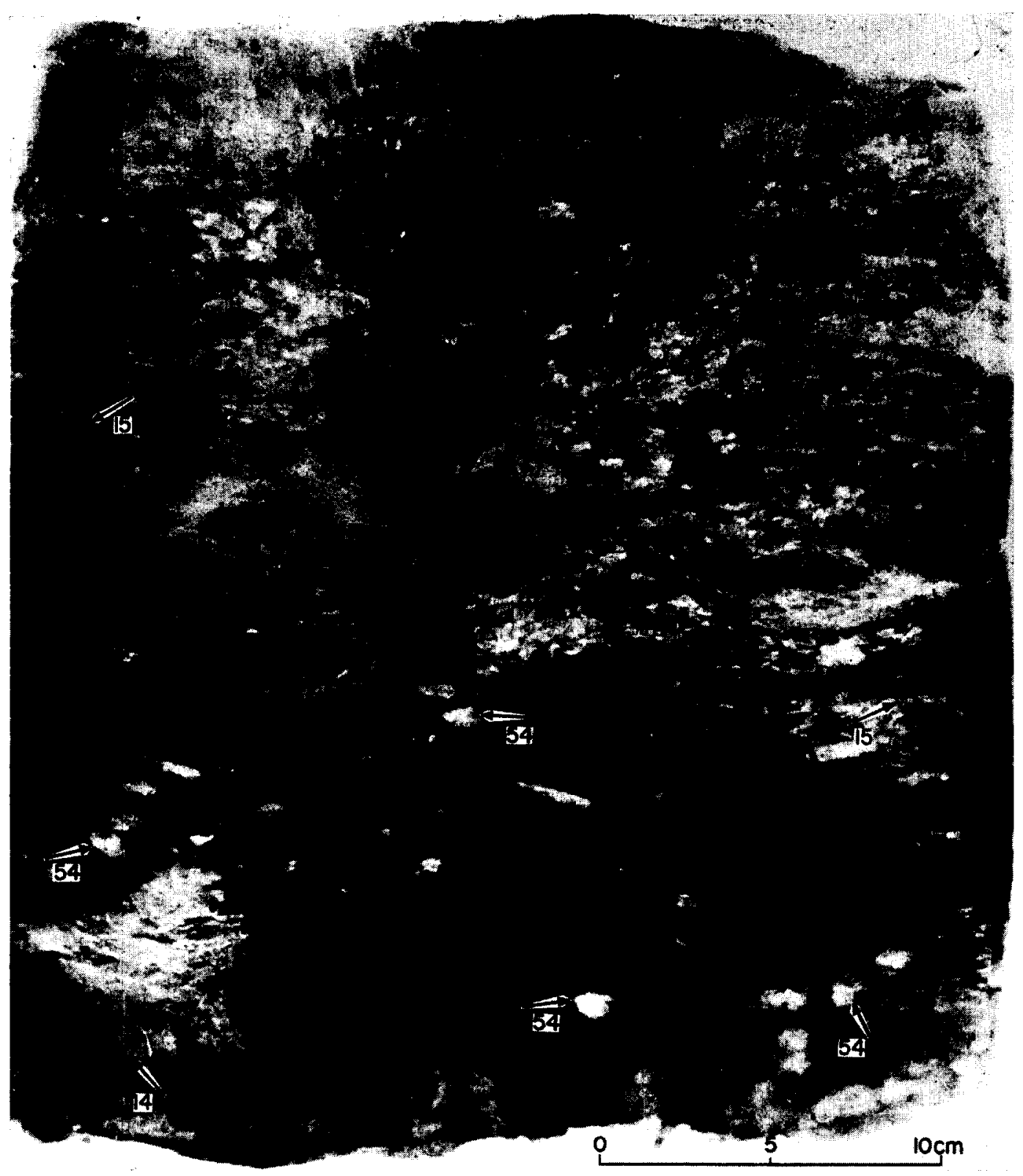

Fig.19. Print of a radiograph made from the slice given in Fig.18. The sediment reveals a mottled structure. Slice thickness: $12 \mathrm{~mm}$. Industrial film, $40 \mathrm{kV}, 5 \mathrm{~mA}, 2 \mathrm{~min}$. 
irregular lines are prints of dust particles (Fig.6, 7, point 14), while the smaller oval light-coloured spots are prints of dry spots (Fig.7, 19, point 15).

\section{Primary and secondary sedimentological properties}

It is impossible to state that all characters visible in a print of a radiograph, which are not discussed in the above paragraph, should be included into the group of sedimentary properties. An attempt is made to explain most of these patterns.

\section{Lithology}

The lithological components can roughly be distinguished within the series of sandsilt-clay. The absorption properties normally decrease with a decrease in grain size, which implies an increase in density of the negative. As a general rule, one can say that within the mentioned sediment series the blackening in the prints increases with increasing sand content (see for example Fig.14, 15, 16, 17).

There are exceptions to this rule (compare Fig.12,13). This is an example of a well-graded Recent turbidite (BoumA, 1964b, c, 1965; BoumA and SHEPARD, 1964). The fact that the lower part of Fig.13 is lighter coloured than the upper part is due to the relative pureness of the lower part. The upper part with parallel lamination and fore-set bedding contains laminae and concentrations of mica which cause the darker lines and bands. Within the lower part of this sample the colour lighthens upward owing to decrease in grain size. The small white spots in the basal part are small shell fragments (point 20).

Fig.11 is a radiograph of a sub-recent estuarine sediment, which represents a typical flaser structure (REINECK, 1960). The alternation of sand and clay is easily visible in a normal photograph, but very thin sand streaks (point 21) in the clay cannot be detected without the application of radiography. The purer the clay, the more homogeneous the light colour (point 24).

\section{Parallel lamination and current-ripple lamination}

These primary sedimentary structures can often be observed easily in sandy sediments without applying any expensive method (Fig.12, point 23). It is possible that a normal photograph does not reveal these properties clearly, and in such cases the radiograph can be quite useful (Fig.14, 15, 16, 17, points 22 and 23). In clayey sediments this is the only way to obtain this information quickly (Fig.1, point 23). Especially for details within the structure, such as undulations and wedging-outs of the laminae, the radiograph may reveal more data (Fig.11, 12, 13, 14, 15, 17, points 22 and 23).

\section{Graded bedding}

Because this structure is only related to grain size and not primarily to differences in mineralogical composition, one should not use radiography as a determination method. The lacquer peel made of the recent turbidite does not show graded bedding, 
while at the same time one gets the impression of a graded bedding by studying the $\mathrm{X}$-ray print (Fig.12, 13, point 25).

In general, graded bedding in a sample consisting of a decrease in sand content and sometimes in size in an upward direction, together with an increase in clay content, can be slightly observed from the radiograph since the blackening decreases upwards (Fig.5).

\section{Inclusions}

They can be detected easily on the radiograph, but their nature can normally not be analysed. The iron oxide concretions which are mainly found in one level of the marsh sample (Fig.1, point 26), but which are also scattered through the sample (point 26) are only slightly different from other images visible in these radiographs.

Clay pebbles also cannot be interpreted on the radiograph (Fig.12, 13, point 27). The bending of the laminae, especially around the upper one, indicate their nature as particle transported as pebble, whereas the halo in the radiograph can hardly explain a burrow. It also seems likely that point 27 in Fig. 11 should be a clay pebble.

Fossils as shells or shell remains can often be studied fairly well in the radiograph. In Fig. 3 (point 28) a Natica sp., and in Fig.10 (point 29) a Cerithium sp. are visible. Both are reworked shells which were not visible at the surface of the slice.

Plant remains are white or very light-coloured on the radiographs. Reworked wood fragments can be seen in Fig.5 (point 30), of which only one is visible in the normal picture (Fig.4, point 30).

\section{Plant remains in situ}

Their reaction to irradiation is similar to that of wood fragments. Roots of Salicornia can be observed as double or single lines running more or less vertical (Fig.1, 10, point 33). It is striking that these roots do not disturb the older sedimentary structures. Fig. 1 also reveals parts of the stem of Spartina (point 34). As discussed in the section "Radiographical techniques and processes", the medical film gives more details of the stems than can be seen in the technical X-ray films.

Compared to the Salicornia roots, the single and double short lines (point 35) in Fig. 11 may be roots of plants growing on top of this sediment section in the temporary excavation in the Haringvliet. They also may be a type of burrows.

The thin lines in Fig.1, on the other hand, could be identified as images from pieces of grass (point 37), but those in Fig.10 could not be interpreted.

\section{Burrows}

The majority of the fine-grained canyon and shelf sediments are more or less completely reworked by organisms. The present author was not able to find animals responsible for these burrows.

In a number of clayey canyon samples the radiograph reveals a typical, more or less horizontal type of burrow (Fig.5, 9, point 38; see also BoumA, 1965). According 
to D. B. Ericson (personal communication, 1963) they may be the trace of a Taonurus sp. or a Zoophycus sp. However, they resemble closely the burrows described by REINECK (1963b, fig.19, 30, 31, 34, 35, 36, 39, 40, 41, 42; personal communication 1964) in sandy deposits made by the echinoid Echinocardium sp. With regard to his fig.31, 40 and 42, it seems likely that the ovals (Fig.5, 9, point 39) are cross-sections from this type of burrows. The latter ones are too regular in size and shape to be indicated as internal load casts.

A number of images in Fig.5 (points 40, 41, 42) shows sufficient criteria to determine them as burrows. Point 40 is a clear example of a vertical burrow that has been cut through obliquely. Point 41 may represent three cross-sections or a spiralshaped type, while the sub-round light-coloured spots should be cross-sections from single burrow tubes (point 42). Point 43 is not too clear. The shape at point 44 is similar to the identical points in Fig.9. These are concentrations of small tube-like burrows (see also fig.15 of BoumA, 1965).

The funnel-shaped form (point 45) at the top of Fig. 17 may certainly have been caused by an animal that lived in the upper part of the sediment near the surface. These types have also been encountered at the top of other samples.

The more or less vertical lines in the clay parts of Fig. 15 certainly are burrows of sandy material in the clay (point 46).

\section{Scour and fill}

The smearing effect of the slicing operation often results in a masking of important characters. This is demonstrated in Fig.16 and 17 (point 31). The upper bedding plane of the clay bed, as can be seen in the photograph, is rather smooth and does not indicate a tendency of irregular scour. The filling of these erosion depressions can only be observed in the radiograph. Point 32 on the photograph points out an uncommon figuration. The idea of a fault may be logical. By comparing this with the radiograph (point 32), it is clear that this too is a type of scour and fill structure.

\section{Slumping}

A number of irregular shapes can be interpreted as the result of slumping. By comparing Fig. 7 with fig. 18 of BoumA (1965) it can be said that the irregular dark-coloured forms in the middle of the photograph are silty lumps that have been replaced a little under the influence of slumping (point 47).

The confused picture given in Fig. 3 can well be explained by a slumping of the entire upper part, presumably a movement over very short distances (in the order $\mathrm{cm}-\mathrm{m}$ ). At point 49 a distorted burrow may be distinguished. In general, one gets the impression that the lower part was bedded or laminated (point 48), while the upper part was practically completely reworked by burrowing animals. Slumping distorted all these properties.

Fig. 17 reveals a number of irregularities which gives the impression of folding (point 50). The increase in dip of the beds upward, together with these irregularities, are all indications of a large slump in downcurrent direction, by which the higher 
parts moved a little further than the lower parts. The wavy laminations (point 23) demonstrate that the actual position of this sand layer is not of sedimentary origin. This idea is confirmed by the presence of the fault (point 51). The sediment part at the right side of this non-artificial fault has moved steeply downward, which resulted in an intensive folding. In the corresponding photograph (Fig.16) one can distinguish a colour contact (point 5). The nature of this line can never be interpreted without consulting the radiograph.

A unique example of slumping can be found at the bottom of the radiograph of sample SJ-45 (Fig.5, point 52). The dark-coloured sandy bands in a clay matrix are bent around and form a slump ball.

\section{Mottled structure}

In many of the radiographs a number of images are still unexplained. Part of them can best be put under the heading "unknown", while other ones can be indicated as "mottling" or "mottled structure". By studying the lower part above the sand bed containing wood rests (Fig.5, point 30), one may consider this coarse mottling as a combination of burrowing and slumping (point 53).

Fig. 19 is entirely mottled. The larger ovals (point 54) may be cross-sections from burrows. The rest of the sample, especially the upper half, is homogeneously mottled, the origin of which cannot be decided positively. The influence of slumping with or without burrowing seems to be likely, presumably a combination with different magnitudes of both.

\section{Other characteristics}

In Fig.15 two zones are present with rather complicated structures (point 55). The photograph (Fig.14) gives only two sand beds, in which the lower one is a little more clayey than the upper one (point 55). No structures are visible. The radiograph shows alternations of black and white colours in an intensely folded pattern. Observations on the sediment slice showed an abundance of fine pieces of organic matter and mica included in the clayey sand. The pattern resembles convolute lamination in a small scale.

The dark points in the upper part of Fig.3 are comparable to the black finegravel pieces in the lower part. From the radiograph their nature cannot be determined. The slice had to be destroyed locally to find gravel.

\section{CONCLUSIONS}

The technique of X-ray radiography as applied to the study of sedimentary structures in consolidated and unconsolidated sediments gives a considerable addition of information formerly unknown. The presence of structures can be detected easily, especially in clayey sediments where other methods produce little information. This method can also be of great help for analysing the exact shape of a structure. 
Besides primary sedimentary structures, a number of secondary properties can often be observed. Especially burrowing and slumping may disturb the original position of lithological units and their structures. It is obvious that radiography should be applied before samples are collected for detailed grain-size analyses or other similar investigations.

The technique should be considered as an additional one and not as a replacement for other methods. The interpretation of the images obtained from a sediment slice can be made directly for a small number of characters, but most of them can only be determined after careful examination of the slice. Exact lithological components cannot be determined directly from the X-ray picture.

It is obvious that $X$-ray radiography will be of great help in our field, but many investigations have to be carried out before its exact value can be stated.

\section{ACKNOWLEDGEMENTS}

The author is indebted to Dr. F. P. Shepard for his permission to work at the box samples collected during sea trips. He is also indebted to Robert L. Wisner for the obtained laboratory facilities, to Neil F. Marshall for his help in slicing and radiographing the samples, to Joop $\mathrm{H}$. Elsendoorn for his photography and to Gerry M. M. Klerkx for all the machine writing. The final manuscript was critically read by Drs. J. R. Curray, D. J. Doeglas and F. P. Shepard. I thank them for their corrections and improvements.

\section{REFERENCES}

Anonymous, 1957. Radiography in Modern Industry, 2 ed. Eastman Kodak Company, X-ray Division, Rochester, N.Y., $136 \mathrm{pp}$.

Anonymous, 1962a. Industriële Röntgenfilms. Gevaert Photo Producten N.V., Antwerpen, 29 pp.

ANonYmous, 1962b. X-ray Films, Screens and Chemicals for Industrial Radiography. Ilford Limited, Ilford, Essex, $27 \mathrm{pp}$.

Bouma, A. H., 1963. Facies model of salt marsh deposits. Sedimentology, 2 : 122-1 29.

Bouma, A. H., 1964a. Sampling and treatment of unconsolidated sediments for study of internal structures. J. Sediment. Petrol., $34: 349-354$.

Bouma, A. H., 1964b. Turbidites. In: A. H. Bouma and A. Brouwer (Editors), Turbidites. Elsevier, Amsterdam, pp.247-256.

Bouma, A. H., 1964c. Ancient and Recent Turbidites. Geol. Mijnbouw, 43 : 375-379.

BoumA, A. H., 1965. Sedimentary characteristics of samples collected from some submarine canyons. Marine Geol., 3 , in press.

Bouma, A. H. Sedimentological methods. In: R. W. FAIRBridge (Editor), Encyclopedia of Earth Sciences, Reinhold, New York, N.Y., in press.

Bouma, A. H. Methods in the Study of Sedimentary Structures. Elsevier, Amsterdam, in preparation.

Bouma, A. H. and Marshall, N. F., 1964. A method for obtaining and analysing undisturbed oceanic sediment samples. Marine Geol., 2 : 81-99.

Bouma, A. H. and ShEPARd, F. P., 1964. Large rectangular cores from submarine canyons and fan valleys. Bull. Am. Assoc. Petrol. Geologists, 48 (2) : 225-231. 
Calvert, S. E. and Veevers, J. J., 1962. Minor structures of unconsolidated marine sediments revealed by X-radiography. Sedimentology, $1: 296-301$.

Hamblin, W. K., 1962. X-ray radiography in the study of structures in homogeneous sediments. J. Sediment. Petrol., 32 : 201-210.

MAarse, M. and Terwindt, J. H. J., 1964. A new method of making lacquer peel sections. Marine Geol., $1: 98-105$.

McMullen, R. M. and Allen, J. R. L., 1964. Preservation of sedimentary structures in wet unconsolidated sands using polyester resins. Marine Geol., 1 : 88-97.

OELE, E., 1964. Sedimentological Aspects of Four Lower-Paleozoic Formations in the Northern Part of the Province of Léon (Spain). Thesis, State Univ., Leiden, 99 pp.

ReIneCK, H. E., 1960. Ueber die Entstehung von Linsen- und Flaserschichten. Abhandl. Deut. Akad. Wiss. Berlin, Kl. III, 1 : 369-374.

ReINECK, H. E., 1963a. Naszhärtung von ungestörter Bodenproben im Format $5 \times 5 \mathrm{~cm}$ für projizierbare Dickschliffe. Senckenbergiana Lethaea, 44 : 357-362.

ReineCK, H. E., 1963b. Sedimentgefüge im Bereich der südlichen Nordsee. Abhandl. Senckenberg. Naturforsch. Ges., $505: 1-138$.

Rioult, M. et RiBY, R., 1963. Examen radiographique de quelques minerais de fer de l'Ordovicien normand. Importance des rayons X en sédimentologie. Bull. Soc. Géol. France, 7 (5) : 59-61. 